\title{
Níveis críticos dos ácidos acético, propiônico e butírico para estudos de toxicidade em arroz em solução nutritiva
}

\author{
Mauricio Marini Kopp ${ }^{1,4}$, Viviane Kopp da Luz ${ }^{2}$ Jefferson Luiz Meirelles Coimbra', \\ Rogério Oliveira de Sousa ${ }^{3}$, Fernando Irajá Félix de Carvalho ${ }^{1}$ e Antonio Costa de Oliveira ${ }^{1}$
}

Recebido em 31/05/2005. Aceito em 23/08/2006

\begin{abstract}
RESUMO - (Níveis críticos dos ácidos acético, propiônico e butírico para estudos de toxicidade em arroz em solução nutritiva). A ocorrência de condições anaeróbias nos solos hidromórficos, associada com a presença de matéria orgânica favorece o desenvolvimento de microrganismos anaeróbios que produzem substâncias fitotóxicas, principalmente ácidos orgânicos de cadeia curta. A seleção de constituições genéticas de arroz promissoras para utilização nestas situações requer avaliações de difícil execução em campo, sendo simplificada pela utilização de sistemas hidropônicos. O objetivo deste trabalho foi determinar a faixa de concentração e as respostas mais apropriadas para serem utilizadas em seleção de genótipos de arroz para tolerância a ácidos orgânicos em sistemas hidropônicos. Foram estudados os efeitos de seis concentrações dos três principais ácidos formados no solo: ácido acético $(0 ; 4 ; 8 ; 12 ; 16$ e $20 \mathrm{mM})$, ácido propiônico $(0 ; 3 ; 6 ; 9 ; 12 ;$ e $15 \mathrm{mM})$ e ácido butírico $(0 ; 2 ; 4 ; 6 ; 8$ e $10 \mathrm{mM})$ em dois genótipos de elevada divergência (BRS-7-TAIM e SAIBAN). Os resultados indicam que as faixas de concentração mais adequadas para estudos de tolerância de arroz a ácidos orgânicos estão entre 8,4 e 15,8; 4,2 e 9,1 e 3,7 e 7,7 mM para os ácidos acético, propiônico e butírico respectivamente, e a variável mais responsiva foi comprimento de raízes.
\end{abstract}

Palavras-chave: Oryza sativa, ácidos orgânicos, toxidez

\begin{abstract}
Critical levels of acetic, propionic and butyric acids for toxicity studies of rice in nutrient solution). The occurrence of anaerobic conditions in hydromorphic soils, associated with the presence of organic matter favors the development of anaerobic microorganisms that produce phytotoxic substances, especially short chain organic acids. Selection of promising rice genotypes for use under these conditions requires difficult field evaluations, which may be simplified with the use of hydroponic culture. The aim of this work was to determine the range of concentration and the dependent variables most appropriate to selecting rice genotypes for tolerance to organic acids in hydroponic culture. Six concentrations of the three main acids formed in the soil: acetic acid $(0 ; 4 ; 8 ; 12 ; 16$ and $20 \mathrm{mM})$, propionic acid $(0 ; 3 ; 6 ; 9 ; 12 ;$ and $15 \mathrm{mM})$ and butyric acid $(0 ; 2 ; 4 ; 6 ; 8$ and $10 \mathrm{mM})$ and two genotypes of high divergence (BRS-7-TAIM and SAIBAN) were used. The results indicate that the most appropriate concentration ranges for studies of rice tolerance to organic acids are: 8.4 and 15.8; 4.2 and 9.1 and 3.7 and $7.7 \mathrm{mM}$ for acetic, propionic and butyric acids, respectively, and the most responsive variable was root length.
\end{abstract}

Key words: Oryza sativa, organic acids, toxicity

\section{Introdução}

A Região Sul do Brasil apresenta uma área de 6,8 milhões de hectares constituída por solos hidromórficos, representando $20 \%$ da área total do Estado do Rio Grande do Sul (Pinto et al. 2004). Nestes solos, a maioria das espécies cultivadas tem seu desenvolvimento e produção prejudicados devido à má drenagem natural que provoca um ambiente anaeróbico, favorecendo a formação de substâncias tóxicas (Camargo et al. 2001). Nestas áreas, onde o solo está praticamente submerso em água, o suprimento de $\mathrm{O}_{2}$ é cerca de 10.000 vezes mais lento que no solo seco (Ponnamperuma 1972). Como a cultura do arroz irrigado tem como característica principal a manutenção de uma lâmina de água sobre o solo durante a maior parte do seu desenvolvimento, o $\mathrm{O}_{2}$ presente é consumido e os microorganismos aeróbios deixam de atuar, proliferando microorganismos anaeróbios, predominantemente bactérias, que utilizam a energia fornecida pela matéria orgânica. Durante a decomposição anaeróbica, formam-se produtos

\footnotetext{
1 Universidade Federal de Pelotas, Faculdade de Agronomia Eliseu Maciel, Centro de Genômica e Fitomelhoramento, Campus Universitário s.n., C. Postal 354, 96010-900 Pelotas, RS, Brasil

2 Universidade Federal de Pelotas, Faculdade de Agronomia Eliseu Maciel, Centro de Genômica e Fitomelhoramento

3 Universidade Federal de Pelotas, Faculdade de Agronomia Eliseu Maciel, Centro de Genômica e Fitomelhoramento, Departamento de Solos, Campus Universitário s.n., C. Postal 354, 96010-900 Pelotas, RS, Brasil

4 Autor para correspondência: marinikopp@gmail.com
} 
intermediários, resultantes principalmente da fermentação, dentre os quais destacam-se os ácidos orgânicos alifáticos de baixo peso molecular (acético, propiônico e butírico), que ocorrem na faixa de concentração de 0,1 a 14 mM (Johnson et al. 2006) e, geralmente, na proporção de 6:3:1 respectivamente (Bohnen et al. 2005). Estes ácidos atingem valor máximo poucos dias após o alagamento, podendo ocorrer toxidez às plantas (Sousa \& Bortolon 2002).

Com a introdução do sistema de plantio direto, que prevê a manutenção de resíduos vegetais sob a superfície do solo, ocorre maior produção de ácidos orgânicos de baixo peso molecular, principalmente em áreas de difícil drenagem natural, o que pode limitar o crescimento e a produtividade do arroz cultivado neste sistema, nestas áreas. A toxidez por ácidos orgânicos manifesta-se, nas fases iniciais de desenvolvimento, por uma menor germinação, menor crescimento radicular, menor peso e altura de plântulas (Sousa \& Bortolon 2002). Em casos de toxidez mais severa, os prejuízos ao crescimento das plantas podem se refletir em outras fases, ocorrendo menor perfilhamento, absorção de nutrientes e rendimento de grãos (Camargo et al. 2001).

Gotoh \& Onikura (1971) demonstraram que a concentração de $5 \mathrm{mM}$ de ácido acético, propiônico e butírico reduziu o crescimento radicular de arroz em 47,$3 ; 63,2$ e $80,8 \%$, respectivamente. Wallace \& Whitehand (1980) verificaram, em trigo, que os ácidos quando adicionados em conjunto aos tratamentos apresentam efeito interativo, aumentando a fitotoxidez final. No entanto, até hoje não foram realizados estudos com o objetivo de verificar o efeito diferencial de um grupo de constituições genéticas frente ao efeito fitotóxico dos ácidos orgânicos.

A identificação e a caracterização da variabilidade genética são o passo inicial e de fundamental importância para o melhoramento genético vegetal. Técnicas de avaliação de genótipos em ambientes controlados com o uso de soluções nutritivas têm sido amplamente utilizados para caracterização de genótipos a diversos estresses (Duncan \& Baligar 1990). Enquanto a avaliação de genótipos em ambientes artificiais não leva em consideração as reais pressões do meio (Duncan \& Baligar 1990), a seleção em ensaios de campo reúne grande número de variáveis não controladas, tais como tolerâncias diferenciais a estresses climáticos, bióticos ou nutricionais (Wright 1989). Correlações significativas entre parâmetros coletados em testes de campo e em ambientes artificiais, com solo ou solução nutritiva foram relatados por Bilinski \& Foy (1987) para diversas gramíneas. Assim, um modo eficiente de avaliação de genótipos para tolerância à presença de ácidos orgânicos em meio de cultivo pode ser realizada em sistemas de hidroponia sob condições controladas.

A deficiente bibliografia disponível evidencia a necessidade de mais estudos com relação as técnicas utilizadas para avaliação da toxicidade por ácidos orgânicos, pois, a maior parte dos trabalhos são antigos e desenvolvidos com tecnologias que não refletem as atuais condições experimentais utilizadas em estudos com hidroponia. Assim, o objetivo do trabalho foi identificar a faixa de concentração e as resposta mais adequadas para estudos de tolerância aos ácidos acético, propiônico e butírico em arroz, utilizando para tal o desempenho de dois genótipos de elevada divergência genética ao estresse causado por cada um dos ácidos.

\section{Material e métodos}

Realizaram-se três experimentos independentes, cada um deles tendo o objetivo de avaliar o efeito dos três principais ácidos orgânicos (acético, propiônico e butírico), provavelmente formados durante a decomposição anaeróbia da matéria orgânica durante a fermentação no solo (Camargo et al. 1993).

Os experimentos foram conduzidos em sistema hidropônico, mediante a aplicação de seis tratamentos e utilização de dois genótipos de elevada divergência genética (BRS-7-TAIM indica e SAIBAN japonica). Foram utilizados potes com capacidade de 5,5 L nos quais foi adaptada uma tela de náilon à tampa para permitir a sustentação das plântulas e o crescimento do sistema radicular no meio de cultivo. Os potes permaneceram em tanque tipo "banho-maria", com temperatura de $25 \pm 1{ }^{\circ} \mathrm{C}$ e iluminação artificial controlada.

A solução nutritiva utilizada apresentou a seguinte composição: nitrato de cálcio - $\mathrm{Ca}\left(\mathrm{NO}_{3}\right)_{2} 4 \mathrm{mM}$, sulfato de magnésio - $\mathrm{MgSO}_{4} 2 \mathrm{mM}$, nitrato de potássio $\mathrm{KNO}_{3} 4 \mathrm{mM}$, sulfato de amônio - $(\mathrm{NH} 4)_{2} \mathrm{SO}_{4}$ 0,435 mM, fosfato potássio - $\mathrm{KH}_{2} \mathrm{PO}_{4} 0,5 \mathrm{mM}$, ácido bórico $-\mathrm{H}_{3} \mathrm{BO}_{3} 10 \mu \mathrm{M}$, molibdato de sódio - $\mathrm{NaMoO}_{4}$ $0,10 \mu \mathrm{M}$, cloreto de sódio $-\mathrm{NaCl} 30 \mu \mathrm{M}$, sulfato de zinco - $\mathrm{ZnSO}_{4} 0,8 \mu \mathrm{M}$, sulfato de cobre - $\mathrm{CuSO}_{4} 0,3 \mu \mathrm{M}$, sulfato de manganês - $\mathrm{MnSO}_{4} 2 \mathrm{mM}$, Ferro EDTA $\mathrm{Fe} \mathrm{SO}_{4}+\mathrm{Na} 10 \mu \mathrm{M}$ (Camargo \& Oliveira 1981).

As sementes de cada genótipo de arroz foram desinfetadas com hipoclorito de sódio a $10 \%$ (produto comercial) por 5 minutos, lavadas em água destilada e 
colocadas para germinação a $25 \pm 1{ }^{\circ} \mathrm{C}$ por 72 horas em papel filtro embebido em água. As plântulas obtidas foram selecionadas quanto a tamanho $(5 \mathrm{~mm})$ e forma. O delineamento experimental utilizado foi o de blocos casualizados, com quatro repetições, e a unidade experimental consistiu de 20 plântulas de cada genótipo para cada repetição. Os tratamentos consistiram de seis concentrações para cada um dos ácidos orgânicos testados (acético, propiônico e butírico). As concentrações utilizadas foram 0 (testemunha); $4 ; 8$; 12; 16 e $20 \mathrm{mM}$, para ácido acético; $0 ; 3 ; 6 ; 9 ; 12$ e $15 \mathrm{mM}$, para ácido propiônico e $0 ; 2 ; 4 ; 6 ; 8$ e $10 \mathrm{mM}$, para ácido butírico. $\mathrm{O} \mathrm{pH}$ foi ajustado para $4,7 \mathrm{com}$ $\mathrm{HCl} 1 \mathrm{~N}$ ou $\mathrm{NaOH} 1 \mathrm{~N}$, sendo monitorado diariamente e ajustado quando necessário, pois segundo Rao \& Mikkelsen (1977a) o pH da solução nutritiva em experimentos com ácidos orgânicos é variável e interfere na toxicidade dos ácidos.

As plântulas permaneceram em solução nutritiva sob os tratamentos por 14 dias. Após esse período elas foram avaliadas quanto aos seguintes caracteres: comprimento de raiz (CR) e parte aérea (CPA), em $\mathrm{cm}$; número de raízes (NR); matéria seca de raízes (MSR) e de parte aérea (MSPA), em mg, após secagem até massa constante em estufa com circulação de ar a $60{ }^{\circ} \mathrm{C}$.

Os dados foram submetidos à análise de variância, ajuste de regressão para cada variável pelo procedimento GLM, Generalized Linear Models, (McCullagh \& Nelder 1989) e teste de correlação de Pearson entre as variáveis estudadas em cada experimento. Todas as análises estatísticas foram realizadas com o programa estatístico SAS (Statistical Analysis System 2002).

\section{Resultados}

A análise de variância mostrou efeitos significativos da interação genótipo $\times$ tratamento para todas as variáveis estudadas em relação ao ácido acético (dados não apresentados). Isto indica que os genótipos apresentaram variações significativas e de magnitudes diferentes frente aos tratamentos utilizados. Quanto ao efeito do ácido propiônico, apenas a variável CR apresentou efeito de interação significativo; no entanto, para todas as outras variáveis pode ser verificada uma variação significativa para efeito de genótipos e tratamentos. O fato de algumas variáveis não apresentarem interação genótipo $\times$ tratamento significativa indica que a variação causada pelo efeito dos tratamentos em ambos os genótipos foi de magnitude semelhante, porém não significa que esta variação deva ser desprezada, pois apresentou efeito significativo para a causa de variação tratamento (Steel \& Torrie 1980). Para o ácido butírico, as variáveis CR e CPA apresentaram variação significativa para interação genótipo $\times$ tratamento. A variável NR, além de não apresentar variação para efeito de interação, não apresentou efeito significativo para efeito de tratamento, indicando que para este ácido, esta variável pode não ser eficiente em discriminar o efeito fitotóxico do elemento estudado. Para as demais variáveis foi constatada significância para efeito de tratamento, indicando serem responsivas ao efeito do ácido, porém com mesma magnitude para ambos os genótipos.

A Fig. 1 ilustra a responsividade das variáveis analisadas frente à ação fitotóxica do ácido acético nos genótipos utilizados. Pode ser verificado que os genótipos apresentaram respostas diferenciais ao efeito dos tratamentos para todas as variáveis analisadas com efeito significativo para interação genótipo $\times$ tratamento. A variável CR foi a que apresentou maior redução relativa frente aos tratamentos com redução média de até $82,4 \%$ na dose mais elevada.. A variável NR foi a única que apresentou acréscimos no seu valor, mostrando também respostas diferentes dos genótipos estudados. Para as variáveis CPA, MSR e MSPA também foi verificada resposta diferencial dos genótipos frente ao estresse. No entanto, as reduções relativas foram muito similares entre si com índices variando de 31,4 a 37,4\% de redução para as variáveis MSPA e MSR, respectivamente, na dose mais elevada.

No experimento relativo à ação fitotóxica do ácido propiônico, os ajustes de regressão (Fig. 2) demonstram que o comportamento médio das variáveis foi similar ao evidenciado com ácido acético. A variável CR foi a de maior responsividade, com redução média de até $84,5 \%$ na dose mais elevada, seguida de CPA com redução relativa de 58,2\%, MSPA, com 29,2\% e MSR, com 25,8\%. A variável NR, também, apresentou acréscimos de valor quando submetida a níveis crescentes de ácido propiônico. Pode ser constatado, analisando a Fig. 2, que os genótipos apresentaram respostas diferenciais apenas para a variável $\mathrm{CR}$, porém com efeitos significativos para a fonte de variação "tratamento" e "genótipos".

No caso do ácido butírico, mais uma vez a variável CR foi a que apresentou maior redução média, chegando neste caso, a uma redução de $78,3 \%$ na dose mais elevada, e respostas diferenciais entre os genótipos utilizados (Fig. 3). A variável CPA, também apresentou efeito de interação entre genótipos $\times$ 
tratamentos porém com reduções relativas médias de aproximadamente $30,5 \%$. A variável NR, neste caso, não apresentou variação significativa para efeito de "interação" ou "tratamento" como pode ser observado na Fig. 3; no entanto, apresenta diferenças entre os genótipos estudados, pois na ausência de efeito de "tratamento" e de "interação", pode-se presumir que as diferenças entre genótipos seja únicamente de cunho genético. Assim como a variável CR, as variáveis MSR e MSPA tiveram reduções relativas médias menores quando comparadas aos outros ácidos testados, com reduções de 14,0 e 11,4\% para MSR e MSPA, respectivamente. Também pode ser evidenciado na figura 3 que apenas para as variáveis $\mathrm{CR}$ e CPA a interação entre genótipos e tratamentos foi significativa, indicando respostas diferenciais entre os genótipos frente os tratamentos.

\section{Discussão}

Armstrong \& Armstrong (2001) estudaram em arroz os sintomas fisiológicos relacionados à toxidez dos ácidos orgânicos aqui estudados e relataram que eles causam degradação da parede celular, inibição das funções respiratórias e, conseqüentemente, diminuição da divisão celular do sistema radicular que está em contato direto com o elemento tóxico, indicando assim a razão principal para o menor crescimento radicular, como também observado por Sousa \& Bortolon (2002). Camargo et al. (2001) e Armstrong \& Armstrong (2001) observaram que as raízes adventícias diminuíam o seu crescimento, promovendo a proliferação de calos na base do coleóptilo, aumentando o número de raízes laterais, sendo esta a provável causa do aumento do número de raízes em arroz quando submetido a
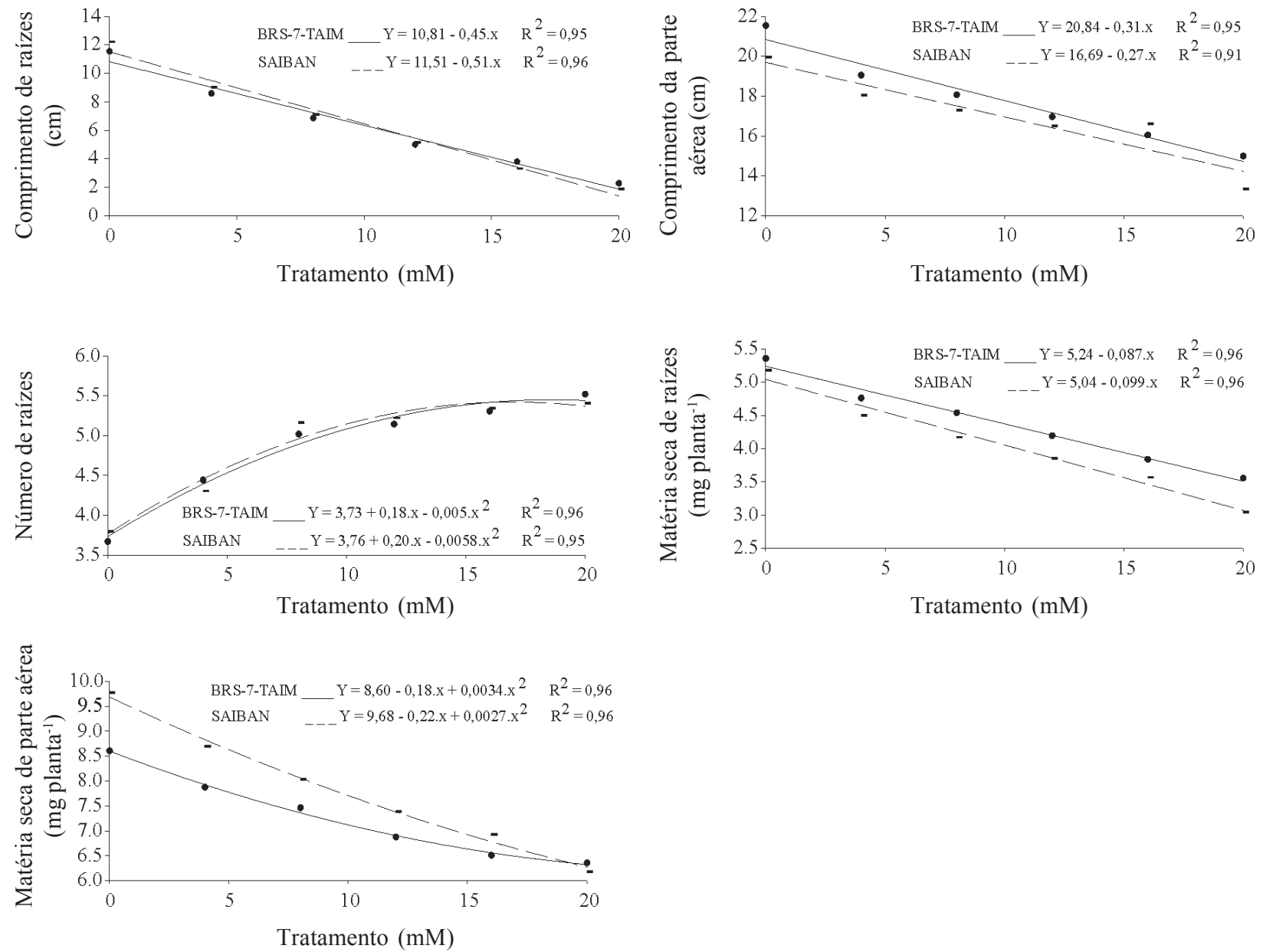

Figura 1. Respostas das variáveis comprimento de raízes (CR), comprimento de parte aérea (CPA), número de raízes (NR), matéria seca de raízes (MSR) e matéria seca de parte aérea (MSPA) em relação a seis concentrações de ácido acético nas cultivares BRS-7-TAIM e SAIBAN. 
tratamentos com os ácidos acético, propiônico e butírico.

Uma variável apropriada para estudos de divergência genética pode ser considerada aquela que apresentar maior magnitude da variação, ou seja, a variável mais responsiva, e que também apresente efeito significativo para interação genótipo $\mathrm{x}$ tratamento, pois discrimina de maneira mais eficiente as diferentes respostas das constituições genéticas frente aos tratamentos (Camargo \& Oliveira 1981; Camargo \& Ferreira 1992; Freitas et al. 2006). No caso deste estudo, a variável que satisfaz estas condições é CR, que apresentou interação significativa em todos os experimentos e elevada variação (Fig. 1, 2 e 3). No entanto, a utilização de apenas dois genótipos pode estar mascarando possíveis resultados de interação e responsividade para as demais variáveis em outras constituições genéticas. O objetivo principal do experimento, porém, foi determinar faixas de concentrações dos ácidos acético, propiônico e butírico, para auxiliar a escolha de tratamentos em experimentos de seleção de constituições genéticas com elevado desempenho para tolerância a ácidos orgânicos.

As concentrações dos ácidos utilizados neste estudo foram selecionados a partir de estudos anteriores, que concluíram que a fitotoxidez dos ácidos orgânicos aumenta na ordem acético, propiônico e butírico, ou seja, quanto maior o tamanho da cadeia de carbonos do ácido, mais tóxico ele é (Takijima 1964; Rao \& Mikkelsen 1977a; b; Krogmeier \& Bremner 1990). Os resultados sugerem que o ácido acético, de fato, se mostrou menos tóxico, pois para promover uma redução de 50\% no comprimento de raízes (variável mais afetada) uma concentração de $10,9 \mathrm{mM}$ foi
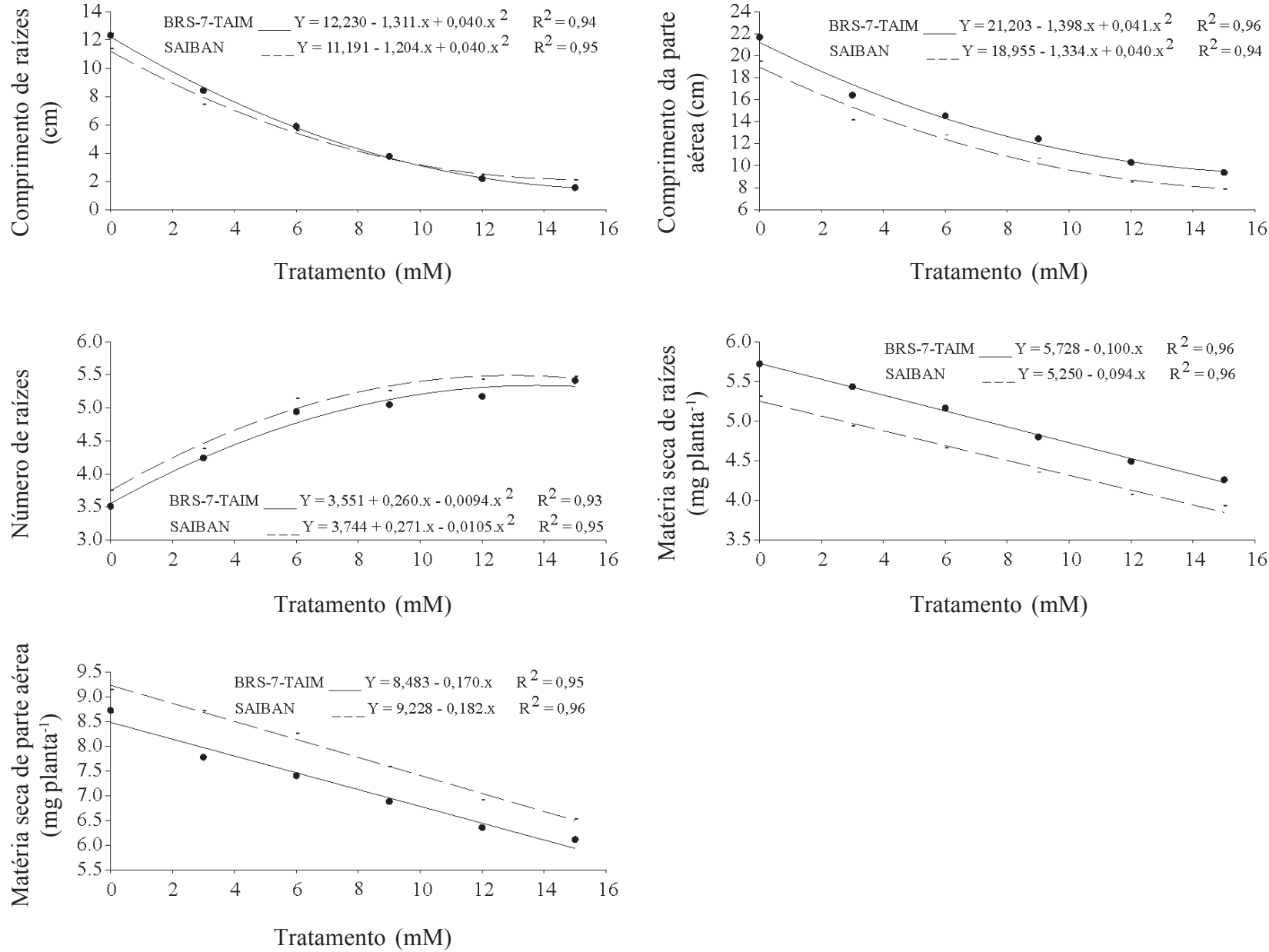

Figura 2. Respostas das variáveis comprimento de raízes (CR), comprimento de parte aérea (CPA), número de raízes (NR), matéria seca de raízes (MSR) e matéria seca de parte aérea (MSPA) em relação a seis concentrações de ácido propiônico nas cultivares BRS-7-TAIM e SAIBAN. 
necessária. No entanto, para os ácidos propiônico e butírico, concentrações de 5,6 e $5,3 \mathrm{mM}$, respectivamente, foram suficientes para promover reduções de 50\% no comprimento de raízes. Assim, pode ser constatado que, de fato, o ácido butírico é o mais fitotóxico, no entanto com pouca diferença em relação ao ácido propiônico, ou seja, seus índices de toxidez são muito semelhantes, contrariando os dados encontrados na literatura, que indicam a necessidade de níveis até $30 \%$ mais elevados de ácido propiônico para promover o mesmo efeito do ácido butírico.

A faixa de concentração sugerida como a mais indicada para produção de estresse em estudos de tolerância a fatores abióticos está entre valores que causem reduções no desempenho das variáveis entre $30 \%$ e $60 \%$ (Jones \& Jones 1992). Estimativas por meio de regressão para a variável mais responsiva
(CR) indicam que estes valores estão entre 8,4 e 15,8 mM para o ácido acético, 4,2 e 9,1 mM para o ácido propiônico e 3,7 e 7,7 mM para o ácido butírico. A utilização de doses que ocasionem reduções muito acentuadas na variável de interesse podem acarretar danos muito acentuados, inibindo totalmente o crescimento de raízes dos genótipos avaliados. Este nível de estresse é indesejável, pois os genótipos não se diferenciam entre si, ocasionando agrupamento de todos eles numa mesma classe de tolerância. Segundo Freitas et al. (2006) a intensidade do tratamento que deve ser utilizado para classificar genótipos quanto à tolerância a estresse por alumínio deve ser tal que promova a distribuição dos genótipos em maior número de classes, possibilitando a discriminação ampla da variabilidade genética entre os acessos avaliados.
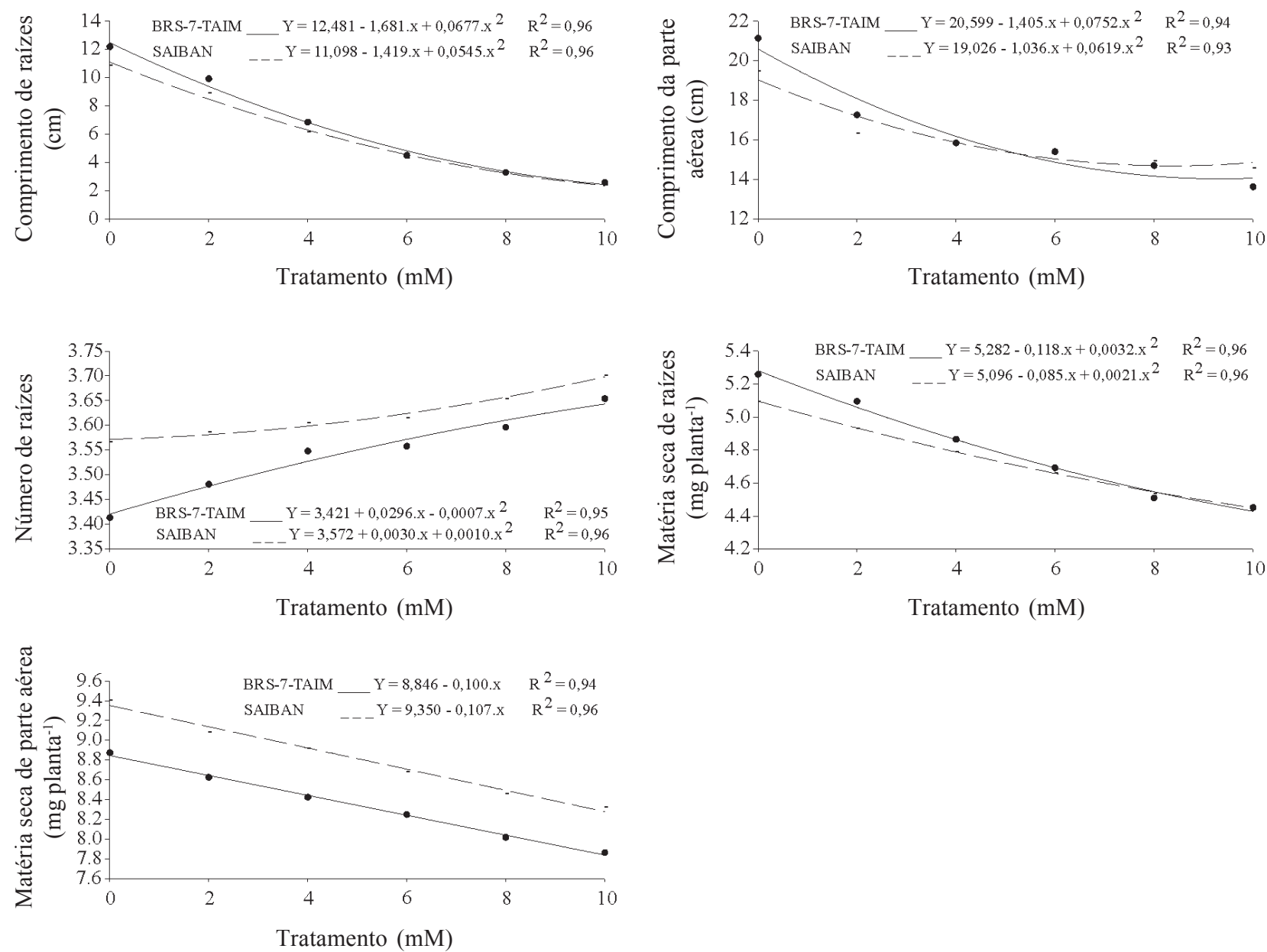

Figura 3. Respostas das variáveis comprimento de raízes (CR), comprimento de parte aérea (CPA), número de raízes (NR), matéria seca de raízes (MSR) e matéria seca de parte aérea (MSPA) em relação a seis concentrações de ácido butírico nas cultivares BRS-7-TAIM e SAIBAN. 
Como já era esperado, devido a sua resposta diferencial na análise de regressão, a variável NR apresentou correlação negativa com as demais, além de ser a única variável que não apresentou correlação significativa com MSR e MSPA no tratamento com ácido butírico (Tab. 1). As demais variáveis apresentaram correlação significativa entre sí em ambos os experimentos. Como a variável mais indicada para avaliação das plântulas foi $\mathrm{CR}$, as variáveis que apresentarem correlação significativa com ela, e também efeito de interação, podem ser utilizadas como forma alternativa ou conjuntamente em seleção indireta para o caráter (Jones \& Jones 1992). Dessa forma, considerando que todas as variáveis se correlacionaram e apresentaram efeitos de interação no tratamento com ácido acético, qualquer variável estudada pode ser utilizada para discriminar genótipos com tolerância a este ácido. No entanto, nenhuma outra variável apresentou efeito de interação no tratamento com ácido propiônico. Assim, apenas a variável CR é indicada para estudos de divergência genética frente ao estresse causado pelo ácido propiônico. Para o ácido butírico, apenas a variável CPA apresentou efeito de interação e correlação com a variável CR, podendo também ser adotada, simultaneamente, para a avaliação de genótipos com tolerância a esse ácido.

Os níveis de tratamentos mais apropriados para estudos de divergência genética para o caráter

Tabela 1. Estimativas de correlação de Pearson entre as variáveis comprimento de raízes (CR), comprimento de parte aérea (CPA), número de raízes (NR), matéria seca de raízes (MSR) e matéria seca de parte aérea (MSPA) avaliadas em 6 níveis de ácido acético, propiônico e butírico.

\begin{tabular}{lcccccc}
\hline Ácido & Variáveis & CR & CPA & NR & MSR & MSPA \\
\hline Acético & CR & 1 & $0,84^{*}$ & $-0,85^{*}$ & $0,85^{*}$ & $0,81^{*}$ \\
& CPA & & 1 & $-0,77^{*}$ & $0,83^{*}$ & $0,70^{*}$ \\
& NR & & & 1 & $-0,79^{*}$ & $-0,77^{*}$ \\
& MSR & & & & 1 & $0,75^{*}$ \\
& MSPA & & & & & 1 \\
Propiônico & CR & 1 & $0,86^{*}$ & $-0,86^{*}$ & $0,77^{*}$ & $0,78^{*}$ \\
& CPA & & 1 & $-0,84^{*}$ & $0,81^{*}$ & $0,68^{*}$ \\
& NR & & & 1 & $-0,77^{*}$ & $-0,69^{*}$ \\
& MSR & & & & 1 & $0,57^{*}$ \\
Butírico & MSPA & & & & & 1 \\
& CR & 1 & $0,65^{*}$ & $-0,32^{*}$ & $0,79^{*}$ & $0,56^{*}$ \\
& CPA & & 1 & $-0,62^{*}$ & $0,43^{*}$ & $0,46^{*}$ \\
& NR & & & 1 & $-0,098$ & $-0,095$ \\
& MSR & & & & 1 & $0,54^{*}$ \\
& MSPA & & & & & 1 \\
\hline
\end{tabular}

* Significativo a $5 \%$ de probabilidade de erro pelo teste $\mathrm{t}$. tolerância a ácidos orgânicos está entre as faixas de 8,4 e 15,8 mM para ácido acético, 4,2 e 9,1 mM para ácido propiônico e 3,7 e 7,7 mM para ácido butírico. $\mathrm{O}$ ácido acético apresenta índice de fitotoxidez inferior ao dos ácidos propiônico e butírico.

A variável comprimento de raízes foi a mais eficiente em discriminar a resposta dos genótipos frente ao estresse causado pelos ácidos acético propiônico e butírico. As variáveis comprimento de parte aérea, número de raízes, matéria seca de raízes e matéria seca de parte aérea também são indicadas para estudos com ácido acético e a variável comprimento de parte aérea, em estudos com ácido butírico.

O genótipo de arroz do grupo indica BRS-7-TAIM apresentou maior sensibilidade ao efeito dos ácidos acético, propiônico e butírico quando comparado ao genótipo japonica SAIBAN.

\section{Referências bibliográficas}

Armstrong, J. \& Armstrong, W. 2001. Rice and Phragmites: effects of organic acids on growth, root permeability, and radial oxygen loss to the rhizosphere. American Journal of Botany 88(8): 1359-1370.

Bilinski, J.J. \& Foy, C.D. 1987. Differential tolerances of oat cultivars to aluminum in nutrient solutions and in acid soils of plant. Journal of Plant Nutrition 10: 129-141.

Bohnen, H.; Silva, L.S.; Macedo, V.R.M. \& Marcolin, E. 2005. Ácidos orgânicos na solução de um gleissolo sob diferentes sistemas de cultivo com arroz irrigado. Revista Brasileira de Ciência do Solo 29(3): 475-480.

Camargo, O.C.E. \& Ferreira, A.W.P. 1992. Tolerância de cultivares de trigo a diferentes níveis de manganês em solução nutritiva. Pesquisa Agropecuária Brasileira 27(3): 417-422.

Camargo, O.C.E. \& Oliveira, O.F. 1981. Tolerância de cultivares de trigo a diferentes níveis de alumínio em solução nutritiva e no solo. Bragantia 49(1): 21-23.

Camargo, F.A.; Santos, G.A. \& Rossielo, R.O.P. 1993. Efeito dos ácidos acético e butírico sobre o crescimento de plântulas de arroz. Pesquisa Agropecuária Brasileira 28(9): 1011-1018.

Camargo, F.A.; Zonta, E.; Santos, G.A. \& Rossielo, R.O.P. 2001. Aspectos fisiológicos e caracterização de toxidez a ácidos orgânicos voláteis em plantas. Ciência Rural 31(3): 523-529.

Duncan, R.R. \& Baligar, V.C. 1990. Genetics, breeding, and physiological mechanisms of nutrient uptake and use efficiency: an overview. Pp. 3-35. In: V.C. Baligar \& R.R. Duncan (eds.). Crops as Enhancers of Nutrient Use. San Diego, Academic Press.

Freitas, F.A.; Kopp, M.M.; Zimmer, P.D.; Sousa, R.O.; Carvalho, F.I.F. \& Oliveira, A.C. 2006. Evalution of aluminum tolerance in rice. Journal of Crop Improvement 16(1/2): 141-151. 
Gotoh, S. \& Onikura, Y. 1971. Organic acids in flooded soil receiving added rice straw and their effect on the growth of rice. Soil Science and Plant Nutrition 17(1): $1-8$.

Johnson, S.E.; Angeles, O.R.; Brar, D.S. \& Buresh, R.J. 2006. Faster anaerobic decomposition of a brittle straw rice mutant: implications for residue management. Soil Biology \& Biochemistry 38: 1880-1892.

Jones, H.G. \& Jones, M.B. 1992. Introduction: Some terminology and commom mechanisms. Pp. 1-10. In: H.G. Jones; T.J. Flowers \& M.B. Jones (eds.). Plants Under Stress. Cambridge, University Press.

Krogmeier, M.J. \& Bremner, J.M. 1990. Effects of aliphatic acids on seed germination and seedling growth in soil. Communications in Soil Science and Plant Analysis 21(7): 547-555.

McCullagh, P. \& Nelder, J.A. 1989. Generalized Linear Models. $2^{\text {nd }}$ ed., London, Chapman and Hall.

Pinto, L.F.E.; Laus, J.A. \& Pauletto, E.A. 2004. Solos de várzea no sul do Brasil. Pp.75-95. In: A.S. Gomes \& A.M. Magalhães Jr. (eds.). Arroz irrigado no sul do Brasil. Brasília, Embrapa-Informação Tecnológica.

Ponnamperuma, F.M. 1972. The chemistry of submerged soils. Advances in Agronomy 24(1): 29-96.

Rao, D.N. \& Mikkelsen, D.S. 1977a. Effect of acetic, propionic, and butyric acids on young rice seedlings growth. Agronomy Journal 69(6): 923-928.
Rao, D.N. \& Mikkelsen, D.S. 1977b. Effect of acetic, propionic, and butyric acids on rice seedlings growth. and nutrition. Plant and Soil 47(6): 323-334.

Sousa, R.O. 2001. Oxirredução em solos alagados afetada por resíduos vegetais. Tese de Doutorado. Universidade Federal do Rio Grande do Sul, Porto Alegre.

Sousa, R.O. \& Bortolon, L. 2002. Crescimento radicular e da parte aérea do arroz (Oryza sativa L.) e absorção de nutrientes em solução nutritiva com diferentes concentrações de ácido acético. Revista Brasileira de Agrociência 8(3): 231-235.

Statistical Analysis System. 2002. SAS: Statistical Analysis System-Getting Started with the SAS Learning Edition. Cary, NC, SAS Institute inc.

Steel, R.G.D. \& Torrie, J.H. 1980. Principles and procedures of statistics: a biometric approach. $2^{\text {nd }}$ ed., New York, McGraw-Hill.

Takijima, Y. 1964. Growth inhibiting action of organic acids and absorption and decomposition of them by soils. Soil Science Plant Nutrition 10(5): 204-211.

Wallace, J.M. \& Whitehand, L.C. 1980. Adverse synergistic effects between acetic, propionic, butyric and valeric acids on the growth of wheat seedling roots. Soil Biology Biochemistry 12: 445-446.

Wright, R.J. 1989. Soil aluminum toxicity and plant growth. Communications in Soil Science and Plant Analysis 20: $1479-1497$. 